\title{
Manajemen Asuhan Kebidanan Masa Nifas pada Ny "S" dengan Nyeri Luka Jahitan Perineum pada Tanggal 24 Juli-03 September 2019 di RSUD Syekh Yusuf Gowa Tahun 2019
}

\author{
${ }^{1}$ Nurul Atikah, ${ }^{2}$ Zelna Yuni Andryani. A, ${ }^{3}$ Dewi Setiawati
}

\begin{abstract}
ABSTRAK
Pendahuluan Nifas adalah masa sesudah persalinan yaitu sejak kelahiran bayi, plasenta dan selaput yang diperlukan untuk memulihkan kembali kesehatan seperti sebelum hamil dengan waktu kurang lebih 6 minggu. Karya tulis ilmiah ini bertujuan untuk melaksanakan manajemen asuhan kebidanan masa nifas pada ibu dengan nyeri luka jahitan perineum di RSUD Syekh Yusuf Gowa Tahun 2019 menggunakan pendekatan studi kasus, dengan metode manajemen asuhan kebidanan tujuh langkah Varney dan pendokumentasian dalam bentuk SOAP. Hasil asuhan pada Ny "S" dengan Nyeri Luka Jahitan Perineum Asuhan dilakukan selama 42 hari dengan melakukan kunjungan masa nifas sebanyak 7 kali, baik di RS maupun di rumah ditemukan ibu mengalami nyeri luka jahitan perineum sejak setelah ibu melahirkan pada tanggal 24 Juli 2019, selama pemantauan tidak ditemukan adanya masalah potensial seperti tanda-tanda infeksi serta pada hari ke 6 masa nifas Ny "S" luka jahitan perineum tampak mulai menyatu dengan kulit dan berangsur sembuh. Kesimpulan dari studi kasus setelah pemantauan dan analisa data pada ibu dengan nyeri luka jahitan perineum di RSUD Syekh Yusuf Gowa tahun 2019 pemantauan masa nifas berjalan normal, tanda-tanda vital dalam batas normal dan telah dilakukan pendokumentasian semua temuan dan tindakan yang telah dilaksanakan pada Ny "S" dengan hasil tidak ditemukannya kesenjangan antara teori dan kasus yang di dapatkan.
\end{abstract}

\section{ABSTRACT}

Introduction postpartum is the post period of childbirth which begins after the birth of a baby. At this time, the placenta and the membranes are needed to restore the health of the mother as the condition prior to pregnancy with a period of approximately 6 weeks. This research paper aims to carry out the postpartum midwifery care management for mothers with perineal suture pain at the Regional Hospital of Syekh Yusuf Gowa. The case study approach was employed in this research in which 7-step Varney obstetric care management method was used. In addition, the documentation of this study was conducted using SOAP documentation form. The treatment on the patient of Mrs. " $S$ " with Perineal Suture Pain was carried out for 42 days by conducting 7 times of postpartum visits, both at the hospital and at her home. The results found that Mrs. " $S$ " suffered from perineal suture pain after she gave birth on July 24, 2019. During the monitoring phase, it is found that there were no potential problems such as signs of infection. In addition, on the 6th day of the puerperium, perineal suture wounds of Mrs. "S" started to fuse with the skin, and they gradually healed. After monitoring process and data analysis on Mrs " $S$ " as the patient with perineal suture pain at RSUD Syekh Yusuf Gowa in 2019, it was found and concluded that the puerperium was normal, and the vital signs were within normal limits. In addition, the documentation form has been carried out on all findings and treatments on the patient of Mrs "S", and it is evident that no gap was found between the theory and the actual case of this study.

\author{
*Universitas Islam Negeri \\ Alauddin Makassar \\ *nurulatikah873@gmail.com
}

Kata kunci :

Masa nifas;

Nyeri luka jahitan perineum;

Langkah varney

Keywords:

Postpartum;

Perineal suture pain;

Varney Steps

\section{PENDAHULUAN}

Asuhan kebidanan merupakan penerapan fungsi dan kegiatan yang menjadi tanggung jawab dalam memberikan pelayanan pada klien yang mempunyai kebutuhan atau masalah dalam bidang kesehatan ibu pada masa hamil, persalinan, maupun nifas. Masa nifas merupakan masa yang rawan bagi ibu, sekitar $60 \%$ kematian ibu terjadi setelah melahirkan dan hampir $50 \%$ dari kematian pada masa nifas terjadi pada 24 jam pertama setelah persalinan, di antaranya di sebabkan oleh adanya komplikasi masa nifas (Saleha,2013:95).

Menurut World Health Organization (WHO) setiap hari terdapat 830 kasus kematian ibu. Di Indonesia AKI tahun 2010-2013 disebabkan oleh perdarahan dan memiliki presentase 
cukup tinggi (Depkes RI, 2014). Penyebab kejadian AKI 40\% adalah perdarahan pada saat postpartum, salah satunya adalah perdarahan akibat robekan perineum.

Menurut data profil kesehatan Dinas Kesehatan Kabupaten Gowa, jumlah Angka Kematian Ibu (AKI) yang dilaporkan oleh Subdin Bina Kesga pada tahun 2015 tercatat kematian ibu nifas sebanyak 8 orang $(57,14 \%)$ dari 14 orang AKI. Tahun 2016 tercatat kematian ibu nifas sebanyak 7 orang dengan (38,89\%) dari 18 orang AKI, dan pada tahun 2017 tercatat kematian ibu nifas 4 orang $(30,77 \%)$ dari 13 orang AKI (Profil Kesehatan Kab.Gowa, 2018).

Menurut data rekam medik RSUD Syekh Yusuf Gowa sendiri pada tahun 2015 tercatat jumlah ibu nifas yang di rawatsebanyak 1804 pasien, tahun 2016 menjadi 1578 pasien, tahun 2017 sebanyak 2012 pasien, sedangkan tahun 2018 sebanyak 2571 pasien. Pada tahun 2018 Sekitar 50\% dari pasien diantaranya mengalami luka jahitan perineum dan mengalami nyeri pada luka jahitan perineum (Rekam Medik RSUD Syekh yusuf Gowa 2019).

Nyeri perineum timbul karena adanya kejadian robekan atau laserasi perineum saat proses melahirkan karena adanya jaringan yang terputus sehingga merangsang hipotalamus untuk mengeluarkan reseptor nyeri pada daerah perineum (Sarwono, 2008). Salah satu faktor yang dapat mempengaruhi nyeri adalah usia. Pada penelitian yang dilakukan Mulati di beberapa BPM di wilayah Kabupaten Klaten, Ibu postpartum pada golongan usia 20-35 tahun yang mengalami nyeri berat sejumlah 28 orang $(30,7 \%)$, nyeri sedang sejumlah 19 orang $(20,8 \%)$ dan nyeri ringan sejumlah 30 orang (32,9\%), Sebaliknya ibu postpartum yang berusia $<20$ tahun tidak ada yang mengalami nyeri berat, mereka hanya mengalami rasa nyeri ringan bahkan ada yang tidak mengalami rasa nyeri meskipun mengalami laserasi perineum (Mulati, 2017:45).

Nyeri perineum bisa menjadi persoalan bagi ibu nifas karena akan menimbulkan gangguan ketidaknyamanan dan kecemasan. Dampak negatif lain diantaranya terhambatnya mobilisasi, terhambatnya proses bounding attachment, perasaan lelah, maupun gangguan pola tidur. Dampak negatif ini bila tidak di atasi akan mempengaruhi proses pemulihan ibu nifas sehingga sangatlah penting untuk mengetahui penanganan yang tepat untuk memperkecil resiko kelainan atau bahkan kematian ibu nifas.

Berdasarkan uraian dan data-data pendukung di atas menunjukkan bahwa masih tingginya kejadian nyeri luka jahitan perineum di RSUD Syekh Yusuf maka penulis tertarik untuk melakukan penelitian tentang Manajemen Asuhan Kebidanan Masa Nifas Pada Ny "S" dengan Nyeri Luka Jahitan Perineum di RSUD Syekh Yusuf Gowa Tahun 2019.

\section{METODE PENELITIAN}

Melaksanakan studi kasus dengan pendekatan Manajemen Asuhan Kebidanan sesuai dengan 7 Langkah Varney dan pendokumentasian dalam bentuk SOAP. Penatalaksanaan Asuhan dilakukan dengan pemberian asuhan yang sesuai standar operasional prosedur pada kasus yang diteliti yaitu Manajemen Asuhan Kebidanan Masa Nifas dengan Nyeri Luka Jahitan Perineum.

\section{HASIL PENELITIAN DAN PEMBAHASAN}

\section{Langkah I (Pengumpulan Data Dasar)}

Pada studi kasus ini dilakukan pengkajian pada Ny "N". Berdasarkan hasil pengkajian dan pemeriksaan yang dilakukan pada Ny "S" dengan Nyeri Luka Jahitan Perineum hari pertama masa nifas ditemukan data ibu dengan adanya ruptur perineum karena posisi ibu yang kurang baik dan benar, pada saat meneran dimana ibu sudah dipimpin mengedan 
dengan baik. Setelah kala II berakhir dilakukan manajemen aktif kala III, setelah plasenta lahir utuh dan lengkap, dilakukanlah penjahitan luka perineum dengan anastesi, penjahitan menggunakan benang plain catgut ukuran 2/0. Penjahitan pada mukosa vagina menggunakan tehnik jelujur, sementara pada perineum menggunakan tehnik satu-satu dengan jumlah jahitan sebanyak 4 dengan jarak setiap jahitan adalah $1 \mathrm{~cm}$ dan jarak antara jahitan terakhir dengan pangkal luka adalah $0,5 \mathrm{~cm}$. Penjahitan dilakukan oleh bidan.

Didapatkan keadaan umum ibu baik, kesadaran komposmentis, ekspresi ibu tampak meringis apabila bergerak. Pemeriksaan tanda-tanda vital yaitu tekanan darah 110/80 $\mathrm{mmHg}$, nadi $80 \mathrm{kali} / \mathrm{menit}$ dan teratur, pernafasan $22 \mathrm{kali} / \mathrm{menit}$, suhu $36,6^{\circ} \mathrm{C}$. Pemeriksaan fisik pada wajah ibu tidak ditemukan oedema, tidak pucat dan ibu tampak meringis, konjungtiva tampak merah muda dan sklera tidak ikterus, payudara simetris kiri dan kanan, putting susu menonjol, tampak hiperpigmentasi areola mammae, tidak ada nyeri tekan dan terdapat pengeluaran colostrum. Tidak ada luka bekas operasi, tampak linea nigra dan striae livide, TFU 1 jari dibawah pusat, kontraksi uterus baik (teraba keras dan bundar). Pada vulva dan perineum tidak ada kelainan, tampak pengeluaran lochea rubra, terdapat luka jahitan yang masih lembab dan tidak berbau serta ekstremitas tidak ada varices dan tidak ada oedema. Pada kasus Ny "S" data yang diperoleh tidak menemukan kesenjangan antara teori dengan kasus yang ditemukan.

\section{Langkah II (Identifikasi Diagnosa atau Masalah Aktual)}

Kasus yang dialami oleh Ny "S", Pasien mengeluh merasakan nyeri pada jahitan bekas robekan pada jalan lahir pada saat setelah melahirkan. Persalinan ibu adalah persalinan anak pertama, dari hasil pemeriksaan vulva dan perineum didapatkan jahitan bekas robekan secara spontan pada perineum ibu, keadaan luka tersebut masih lembab, jahitan masih dalam keadaan basah, kondisi luka tidak menunjukkan adanya oedema dan tidak ada tanda-tanda infeksi pada luka perineum seperti adanya pus/nanah, bau busuk dan suhu sekitar luka lebih tinggi dari pada suhu tubuh ibu.

Pada hari pertama sampai hari kedua masa nifas sangatlah rentan akan terjadinnya infeksi, karena pada waktu inilah luka masih dalam keadaan lembab dan keadaan luka masih basah diakibatkan karena lochea yang keluar dari jalan lahir akan melewati luka tersebut. Infeksi nifas yaitu infeksi bakteri pada dan melalui traktus genetalia yang terjadi sesudah melahirkan, ditandai dengan kenaikan suhu sampai $38^{\circ} \mathrm{C}$ atau lebih selama 2 hari dalam 10 hari pertama pasca persalinan, dengan mengecualikan 24 jam pertama. Dengan demikian penerapan tinjauan teori pada studi kasus $\mathrm{Ny}$ "S" tidak temukan kesenjangan antara teori dengan kasus yang ditemukan.

\section{Langkah III (Identifikasi Diagnosa atau Masalah Potensial)}

Berdasarkan kasus Ny "S" saat ini dengan nyeri luka perineum akibat rusaknya otototot dari terjadinya robekan secara spontan, terdapat pegeluaran lochea pada jalan lahir, hal inilah yang dapat memicu terjadinya infeksi luka perineum.

Vagina merupakan organ terbuka yang mudah dimasuki kuman dan mengakibatkan terjadinya infeksi berdasarkan data yang ada pada studi kasus Ny "S" dapat diidentifikasi masalah potensial yaitu antisipasi terjadinya infeksi. Dengan demikian penerapan teori dan manajemen asuhan kebidanan pada studi kasus Ny "S" nampak ada persamaan dan tidak ditemukan adanya kesenjangan.

\section{Langkah IV (Tindakan Emergency atau Kolaborasi)}

Berdasarkan kasus Ny "S" selama pemantauan, masa nifas ibu berjalan normal dan tidak ada komplikasi yang menyertai sehingga tidak diperlukan adanya tindakan segera atau emergency. 


\section{Langkah V (Merencanakan Asuhan yang Menyeluruh)}

Berdasarkan kasus yang terjadi pada Ny "S" yaitu memberitahu ibu penyebab dari nyeri yang dirasakan oleh ibu, nyeri pada luka perineum disebabkan oleh karena terputusnya jaringan atau otot-otot perineum akibat terjadinya robekan baik disengaja maupun robekan spontan maka aliran darah pada jaringan tersebut terhambat dan mengantarkan respon nyeri ke hypothalamus dan presepsikan ke saraf perifer dan menimbulkan nyeri

Rencana asuhan yang diberikan adalah memberitahu ibu penyebab dari nyeri yang dirasakan oleh ibu selain menjelaskan penyebab nyeri yang dirasakannya, dilakukan pula observasi kontraksi uterus karena dengan mengobservasi kontraksi uterus yang baik merupakan salah satu upaya pencegahan postpartum yang diakibatkan oleh atonia uteri dan memperlambat proses involusi.

Observasi pengeluaran lochea yang merupakan cairan ekskresi selama nifas juga hal penting yang harus dilakukan. Pengeluaran lochea ini menjadi salah satu tanda berjalannya proses involusi uterus.

Melakukan perawatan luka perineum dapat mencegah terjadinya infeksi dan mempercepat proses penyembuhan. Luka perineum merupakan rusaknya jaringan otot-otot perineum, dimana luka tersebut berada di daerah yang lembab dan rentan akan masuknya kuman. Adapun tanda-tanda infeksi pada luka perineum ialah pada luka jahitan terdapat pus/nanah, adanya bau busuk, suhu perineum lebih hangat dari suhu sekitarnya.

Berdasarkan kasus Ny "S" bidan melakukan pemberian obat analgetik, antibiotik dan multi vitamin sebagai upaya untuk mencegah terjadinya infeksi. Obat analgetik dapat mengurangi rasa nyeri yang dialami ibu dan obat antibiotik dapat menghambat mikroba atau jenis lain penyebab infeksi. Serta dengan pemberian zat besi pada ibu nifas karena di masa nifas kebutuhan Fe meningkat akibat kehilangan darah pada saat proses persalinan (Saleha, 2013:131-132).

Pada langkah ini penulis tidak menemukan kesenjangan antara teori dan kasus yang didapatkan. Dimana rencana asuhan yang diberikan pada Ny "S" berdasarkan teori memiliki kesamaan dengan kasus yang didapatkan.

\section{Langkah VI (Implementasi)}

Berdasarkan kasus yang terjadi pada Ny "S" Kunjungan di rumah sakit dilakukan sebanyak tiga kali yaitu pada tanggal 24 Juli 2019 didapatkan nyeri yang dirasakan ibu dalam kategori nyeri berat terkontrol dimana ibu masih respon terhadap tindakan, sifat nyeri lebih terasa jika banyak bergerak. Asuhan yang diberikan yaitu menjelaskan penyebab nyeri yang dirasakan, menganjurkan ibu untuk melakukan teknik relaksasi, selalu menjaga kebersihan diri (Personal hygiene). Hari kedua tanggal 25 Juli 2019 setelah dilakukan implementasi didapatkan nyeri yang dirasakan ibu dalam kategori nyeri sedang, ibu belum dapat beraktivitas seaktif biasanya.

Asuhan yang diberikan yaitu menganjurkan ibu untuk tetap melakukan teknik relaksasi dan mobilisasi untuk mengurangi rasa nyeri dan pada hari ketiga kunjungan rumah sakit tanggal 26 Juli 2019 hasil ibu sudah mampu beradaptasi dengan nyeri yang di rasakan dan selain mengobservasi keadaan ibu tambahan informasi yang diberikan yaitu perawatan bayi, anjuran untuk tidak melakukan hubungan seksual selama 6 minggu, konseling KB.

Kunjungan dilanjutkan ke rumah ibu dilakukan sebanyak empat kali dimulai pada tanggal 29Juli 2019-03 September 2019 hasil keadaan ibu kesadaran komposmentis, tandatanda vital dalam batas normal mengobservasi tinggi fundus uteri, kontraksi uterus dan pengeluaran lochea. Mengajarkan ibu massase fundus, personal hygiene terutama vulva hygiene, health education, anjuran untuk makan makanan bergizi untuk mempercepat proses 
penyembuhan dan berkaitan dengan produksi ASI, melakukan teknik relaksasi, mobilisasi dan menyusui anaknya agar membantu proses involusi uterus, anjuran untuk tidak melakukan hubungan seksual selama 6 minggu, konseling KB, pemberian support dari keluarga khususnya suami sangat penting untuk membantu proses adaptasi terkait nyeri yang dirasakan ibu dan selalu mengingat dan berserah diri kepada Allah SWT dengan caraberdoa dan mendengarkan lantunan ayat suci Al-Qur'an. Adapun beberapa tambahan asuhan yang diberikan yaitu perawatan bayi baru lahir serta jadwal pemberian imunisasi.

Pada langkah ini penulis tidak menemukan hambatan yang berarti dalam memberikan asuhan kebidanan karena seluruh tindakan yang dilakukan telah mengarah dan sesuai dengan kebutuhan pasien.

\section{Langkah VII (Evaluasi)}

Pada kasus Ny"S" dari hasil evaluasi setelah asuhan kebidanan yang dilaksanankan selama 42 hari dengan 7 kali kunjungan pada kasus nyeri luka jahitan perineum yang dialami Ny "S" yakni pada tanggal 24 Juli 2019 sampai dengan tanggal 26 Juli 2019 dilakukan di rumah sakit dan kunjungan rumah pada tanggal 29 Juli 2019 sampai dengan berakhirnya masa nifas tanggal 03 September 2019 tidak di temukan adanya komplikasi yang signifikan dan hasil yang didapatkan setelah dilakukan implementasi secara keseluruhan ibu mampu beradaptasi dengan nyeri yang dirasakan ditandai dengan tanda-tanda vital dan pemeriksaan fisik lainnya dalam batas normal dan ekpresi ibu tampak ceria. Hal ini sesuai dengan manajemen asuhan sesuai dengan teori dan sesuai dengan wewenang bidan.

\section{KESIMPULAN DAN SARAN}

\section{A. Kesimpulan}

1. Telah dilaksanakan pengkajian dan analisis data ibu nifas pada Ny "S" dengan nyeri luka jahitan perineum pada tanggal 24 Juli-03 September di RSUD Syekh Yusuf Gowa Tahun 2019. Hasil dari analisa data didapatkan ny "S", umur 26 tahun, PIA0 dengan nyeri luka jahitan perineum setelah melahirkan pada tanggal 24 Juli 2019, pukul 12.35 Wita.

2. Telah dirumuskan diagnosa/masalah aktual ibu nifas pada Ny "S" pada tanggal 24 Juli-03 September di RSUD Syekh Yusuf Gowa Tahun 2019. Hasil dari interpretasi data sehingga Ny "S" umur 26 tahun dengan masalah aktual nyeri luka jahitan perineum

3. Telah dirumuskan diagnosa/masalah potensial ibu nifas pada Ny "S" dengan nyeri luka jahitan perineum pada tanggal 24 Juli-03 September di RSUD Syekh Yusuf Gowa Tahun 2019. Hasil dari interpretasi data Ny "S" berpotensial infeksi luka jahitan perineum.

4. Telah mengidentifikasi perlunya tindakan segera dan kolaborasi ibu nifas pada $\mathrm{Ny}$ "S" dengan nyeri luka jahitan perineum pada tanggal 24 Juli-03 September di RSUD Syekh Yusuf Gowa Tahun 2019. Hasil yaitu tidak diperlukan adaanya tindakan segera/emergency.

5. Telah menetapkan rencana tindakan asuhan kebidanan ibu nifas pada $\mathrm{Ny}$ "S" dengan nyeri luka jahitan perineum pada tanggal 24 Juli-03 September di RSUD Syekh Yusuf Gowa Tahun 2019 berdasarkan diagnosa/ masalah aktual dan masalah potensial seperti perawatan luka perineum, teknik relaksasi dan mobilisasi dini, pemantauan tinggi fundus uteri, pengeluaran lochea, pemberian ASI ekslusif, personal hygiene, $\mathrm{KB}$, pemberian support, dsb. 
6. Telah melaksanakan tindakan asuhan yang telah disusun pada ibu nifas Ny "S" dengan nyeri luka jahitan perineum pada tanggal 24 Juli-03 September di RSUD Syekh Yusuf Gowa Tahun 2019 dengan hasil yaitu semua perencanaan dapat dilaksanakan seluruhnya dengan baik tanpa hambatan.

7. Telah mengevaluasi hasil tindakan yang telah dilakukan pada ibu nifas Ny "S" dengan nyeri luka jahitan perineum pada tanggal 24 Juli-03 September di RSUD Syekh Yusuf

8. Gowa Tahun 2019 dengan hasil yaitu seluruh asuhan telah diberikan dan tidak ada hal yang menyimpang dari evaluasi tinjauan teori

9. Telah dilakukan pendokumentasian semua temuan dan tindakan yang telah dilakukan pada ibu nifas Ny "S" dengan nyeri luka jahitan perineum pada tanggal 24 Juli-03 September di RSUD Syekh Yusuf Gowa Tahun 2019 dalam bentuk SOAP.

\section{B. Saran}

\section{Untuk Klien}

Diharapkan kepada ibu masa nifas dapat meningkatkan kondisi fisik dan psikis, serta personal hygiene untuk menghindari komplikasi yang lebih berat dalam masa nifas utamanya pada ibu nifas dengan nyeri luka jahitan perineum untuk mencegah terjadinya infeksi pada ibu.

Diharapkan pada setiap ibu nifas agar mengkomsumsi makanan yang bergizi karena makanan yang bergizi akan memenuhi kebutuhan energi, juga untuk mempercepat proses penyembuhan dan pengembalian alat reproduksi mendekati keadaan sebelum hamil serta untuk memperbanyak produksi ASI.

Diperlukan keterlibatan suami/keluaga dalam perawatan untuk meningkatkan hubungan yang lebih erat antar pasien dengan bayinya demi menambah pengetahuan dan bimbingan sebagai lanjutan perawatan dirumah.

Untuk bidan

Sebagai petugas kesehatan khususnya seorang bidan diharapkan senantiasa berupaya untuk meningkatkan pengetahuan dan keterampilan dalam melaksanakan pelayanan kesehatan yang lebih profesional berdasarkan manajemen kebidanan sebagai pertanggung jawaban.

Dalam melaksanakan tugas sebagai bidan harus sepengetahuan dan mendapatkan persetujuan dari klien

Dalam pandangan Islam dalam memberikan asuhan kepada klien harus menerapkan kaidah agama di dalamnya agar klien dapat mengerti tentang larangan dalam melakukan hubungan badan antara suami istri apabila dalam keadaan haid atau nifas.

\section{Untuk Institusi Pendidikan}

Dengan mengetahui permasalahan yang dapat timbul pada ibu nifasdengan nyeri luka jahitan perineum, diharapkan intitusi pendidikan dapat meningkatkan mutu dan kualitas serta perkembangan sesuai prosedur dalam memberikan asuhan dan dalam pelaksanaan manajemen asuhan kebidanan dalam memecahkan suatu masalah kebidanan.

\section{DAFTAR PUSTAKA}

Depkes RI. 2014. Profil Kesehatan Indonesia 2014.

Fatimah dan Lestari, Prasetya. 2019. Pijat perineum Mengurangi Rupture Perineum untuk Kalangan Umum, Ibu Hamil, dan Mahasiswa Kesehatan.Yogyakarta: Pustaka Baru Press 
Lestari, P. 2016. Usia Berpengaruh Dominan Terhadap Perilaku Perawatan Luka Perineum pada Ibu Nifas di RSUD Sleman. Jurnal Ners Dan Kebidanan Indonesia, 4(2), 95. https://doi.org/10.21927/jnki.2016.4(2).95-101

Mulati, T. S. 2016. "Pengaruh Derajat Laserasi Perinium Terhadap Skala Nyeri perinium Pada Ibu Post Partum (Triwik Sri Mulati) 1". 1-9.

Mulati, T. S. 2017. "Nyeri perineum berdasarkan karakteristik pada ibu post partum”. Jurnal Involusi Kebidanan, 7(13).

Maritalia, Dewi. 2012. Asuhan Kebidanan Nifas dan Menyusui. Yogyakarta: Pustaka Pelajar.

Marmi. 2012. Asuhan Kebidanan pada Masa Nifas "Peurperium Care”. Yogyakarta: Pustaka Pelajar.

Maryunani Anik. 2011. Asuhan Pada Ibu Dalam Masa Nifas (Postpartum). DKI Jakarta: CV. Trans Info Medika

Pollard Maria. 2016. ASI Asuhan Berbasis Bukti. Jakarta: EGC

Prawirohardjo, Sarwono. 2008. Ilmu Kebidanan. Jakarta: PT Bina Pustaka Sarwono Prawirohardjo.

Profil Kesehatan Kabupaten Gowa 2018.

Saleha Sitti. 2013. Asuhan Kebidanan Pada Masa Nifas. Jakarta: Salemba Medika.

Tanra Andi Husni, ddk. 2017. Dasar Manajemen Nyeri \& Tatalaksana Multi Teknik Patient Controlled Analgesia. Jakarta: Sagung Seto

Tulas, V., Kundre, R., \& Bataha, Y. 2017. "Hubungan Perawatan Luka Perineum Dengan Perilaku Personal Hygiene Ibu Post Partum Di Rumah Sakit Pancaran Kasih Gmim Manado". Jurnal Keperawatan, 5(1).

Walyani, Elisabeth Siwi. 2015. Asuhan Kebidanan Kegawatdaruratan Maternatal \& Neonatal. Yogyakarta: Pustaka Baru Press.

Walyani, Elisabeth Siwi dan Th. Endang Purwoastuti. 2015. Asuhan Kebidanan Masa Nifas \& Menyusui. Yogyakarta: Pustaka Baru Press. 